\title{
The teaching of human genetics in schools
}

\author{
J S FITZSIM MONS
}

From the Clinical Genetic Service, City Hospital, Hucknall Road, Nottingham NG5 1PB.

Most genetic counsellors stress the importance of ensuring that persons being counselled have an understanding of the facts and make their decisions on an informed basis. However, the extent to which this is achieved varies considerably and where clients' knowledge of the disease and the inheritance pattern has been assessed it is clear that many of them fail to assimilate and recall even simple facts related to their disorder. Most clinics have experience of persons who know nothing of genes or chromosomes, are unfamiliar with the concept of cell division, and yet may have to grapple with difficult ethical and moral decisions about their reproductive lives. In such circumstances the counsellor and counsellee face a formidable task and ensuring a basic understanding of simple biological mechanisms may be extremely difficult. As might have been anticipated, several studies have demonstrated the value of previous education in biology as an important determinant of the client's attainment of genetic knowledge in the counselling clinic. ${ }^{1}$ Leonard et $a l,{ }^{2}$ in their investigation of 78 couples who had a child with one of four disorders, further confirmed that in addition to improving their understanding of the problem, the parents' knowledge of biology also helped in their grasp of probability. These and other findirigs, coupled with the increasing complexity of the decisions facing those with genetic disease, have prompted a number of professionals in medicine and education to recommend that human biology and genetics should receive greater attention in the classroom. Scriver et $a l,{ }^{3}$ in their study of 930 high school students in Canada, confirmed that young people also had a strong preference for more and earlier teaching of these subjects.

In the present education system in England, pupils normially do not commence their study of biology until they start secondary education at the age of 11 years. In primary school (aged 5 to 11 years) they have lessons on nature study or exploratory science,

Received for publication 12 April 1983. Accepted for publication 19 April 1983. are generally taught how to recognise the difference between various types of plants and animals, and are introduced to simple physiology and growth. Some primary schools may have occasional discussion on reproduction, usually relevant to a variety of school pets. There is unlikely to be any structured teaching on human biology or reproduction, although a school nurse or interested health visitor may be drafted for one or more sessions of this sort. In the state secondary schools, either comprehensive or grammar, all pupils irrespective of ability will have some core teaching in basic biology for the first 2 or 3 years. During that time they will be made familiar with the variety of life and progress to physiology and anatomy of plants and animals. Reproduction will be discussed at various levels and there is emphasis on subjects such as food and diet, care of teeth, and hygiene. Up until a few years ago, genetics was considered to be a sixth form topic suitable for the more able pupils and there is still unlikely to be much pressure to introduce it in the first few years of secondary education. In the third or fourth years, pupils at comprehensive school will be sub-divided into those who will take a course leading to the Certificate of Secondary Education (CSE), those who will take the course for the General Certificate of Education (GCE) at ordinary level (O level) or later at advanced level (A level), and those who will not take any examinations. All pupils at grammar schools will be expected to take examinations and there are still a number of areas in the country where this ıype of school persists. Those pupils not taking further examinations will coniinue with some science subjects and may take courses such as 'science-atwork' or 'body maintenance', both of which will include some further basic human biology with an emphasis on topics such as hygiene and nutrition. These tend to be packaged courses organised by individual schools and do not generally rely on recommended texts. Some schools, however, may use science or biology textbooks normally recommended for the CSE or O level examination syllabuses. It is 
unlikely that any of them will contain much reference to inheritance or simple genetics. In the fifth and final year at secondary school, non-examination pupils may have some further teaching in human biology, perhaps as part of a course on social biology.

Pupils taking the CSE examinations normally follow a syllabus laid down by regional rather than national boards. The East Midland Regional Examination Board, fairly typical of those elsewhere in the country, has three syllabuses in biology at various levels or modes. Mode 1 is normally recommended for the more able pupils, but all have much the same stated objectives and are designed to develop and encourage an attitude of enquiry and to instil an awareness of the place of biology in the world at large. Syllabus 1 includes the study of a fairly wide range of plants and animals, including man, to illustrate general biological principles including nutrition, respiration, transport, excretion, coordination, and reproduction. Variation and heredity is included and there is a statement to the effect that a knowledge of the existence of chromosomes, but not of their behaviour during nuclear divisicn, would be expected. Part 2 of the same syllabus suggests more detailed study of a particular aspect of biology, such as social biology, containing reference to various social problems associated with smoking, drugs, alcohol, obesity, birth control, and venereal disease. In biology syllabus 2 , the topics are somewhat similar, but genetics and evolution are included as the final item. This latter is further sub-divided into inheritance, the material of inheritance, the origin of characteristics, development, different ways of breeding, and evolution. Nowhere is the social significance of inheritance or genetic disease mentioned, nor does the syllabus on social biology have any reference to the social impact of disease.

At $\mathrm{O}$ level, human biology may be taken as an option although general biology appears to be more popular with the majority of pupils. The syllabuses recommended for $\mathrm{O}$ and $\mathrm{A}$ level are those of naticnal rather than regional boards and there is some variation between the five or so well recognised ones. A typical biology syllabus, recommended by one of the national boards (the Joint Matriculation Board), lists variation and heredity at the end of the course and, in addition to heritable and non-heritable variation, includes an outline of mitosis and Mendel's monohybrid experiments. Pupils are also expected to be aware of chromosomes as the site of genetic material, sexual reproduction as a process of genetic reassortment, and something of selection leading to evolutionary change. The syllabus for human biology, which may be taken as an alternative subject, also includes a section on variation and heredity and, in addition, candidates are expected to be aware of chromosomes as the site of genetic material and to know about the role of DNA. Other topics include the chromosomal basis of sex determination, meiosis, and the simple genetics of ABO blood groups. Pupils are also expected to know one human disease related to heredity. Genetics is left until late in biology courses and this may present problems as the examination approaches.

The Joint Matriculation Board's biology syllabus for pupils sitting A level examinations lists variation and heredity earlier in the course and, in addition to the previous recommendations for $\mathrm{O}$ level, includes: "Sufficient knowledge of the structure and behaviour of chromosomes and genes to understand mono- and dihybrid crosses, backcross, linkage (numerical treatment of linkage not required). Sex chromosomes and linkage, parallel behaviour of genes and chromosomes. The concept of gene pool. The Hardy-Weinberg formula and its application."

Although recommending a more detailed knowledge of basic genetics, this syllabus like the others has no reference to the sccial relevance of genetic disorders.

The number of pupils chocsing biology as an examination subject can be seen from figures supplied by the Department of Education and Science (table). In the school year 1980 to 1981 , approximately $40 \%$ of all pupils attempted O or CSE level examinations in some aspect of biology, and approximately $27 \%$ obtained an $O$ level pass or equivalent. Eighteen percent of all school leavers progressed to A level examinations in any subject and of these only approximately $22 \%$ sat $\mathrm{A}$ level biology. The distribution of the entries by sex suggests that biology is more popular with girls than boys and although the choice of examination subject for A level will be dependent on career choice, the

TABLE No of pupils choosing biology as an examination subject.

\begin{tabular}{|c|c|c|c|}
\hline & Boys & Girls & Total \\
\hline $\begin{array}{l}\text { School leavers 1980-1981 (000s) } \\
\text { (England) }\end{array}$ & & & $733 \cdot 96$ \\
\hline \multicolumn{4}{|l|}{ O/CSE entries* } \\
\hline Biology (1) & $106 \cdot 66$ & $199 \cdot 01$ & $305 \cdot 67$ \\
\hline Any subject & $329 \cdot 89$ & $327 \cdot 07$ & $656 \cdot 96$ \\
\hline \multicolumn{4}{|l|}{ A entries } \\
\hline Biology (1) & $13 \cdot 20$ & 17.43 & $30 \cdot 63$ \\
\hline Any subject & $70 \cdot 70$ & $64 \cdot 83$ & $135 \cdot 53$ \\
\hline \multicolumn{4}{|l|}{ Leavers attempting } \\
\hline CSE examinations & & & $557 \cdot 88$ \\
\hline O level examinations & & & $431 \cdot 35$ \\
\hline A level examinations & & & $135 \cdot 53$ \\
\hline
\end{tabular}


apparent lack of enthusiasm for biology is surprising. This may reflect the current view held by many teachers that it is a lower status examination subject. Human biology is not available as an option at $\mathrm{A}$ level and is generally not essential for entry to medical school. It would appear, therefore, that significantly less than half of all pupils leaving our schools have had teaching leading to examination in biology, and this is similar to the frequency reported from North America. The figures also confirm that approximately $10 \%$ of all school leavers sat no examination throughout their secondary school career, although some of them will have had teaching in biology.

Although genetics would normally be taught as part of biology or human biology, the time devoted to it will be dependent on various factors, including the teachers' training in genetics and the availability of appropriate texts for the pupils. Unfortunately, most standard texts on biology, although excellent in many other respects, do not have human biology and genetics as major components and very rarely is the social relevance of genetics mentioned. Six current popular standard textbooks of biology* were recently reviewed and their genetic and human biology content assessed. The percentage of the total pages devoted to genetics varies from none in one introductory text to a maximum of $10 \%$ with an average of $6 \%$. In all, the emphasis was on non-human examples of most biological principles. None stressed the practical relevance of hereditary diseases and in only one was there reference to genetic counselling. Karyotypes were poorly and rarely presented, despite their obvious interest. A survey by Mertens and Bowman ${ }^{4}$ of 13 general biology textbooks available in colleges in the United States produced similar findings and, although all contained some reference to various types of genetic disease, there was very considerable variation in the emphasis given to the social application of medical genetics. They concluded that human genetics is not a major concern of the author of biology textbooks and as a consequence they made several recommendations for the improvement of the human genetic content of biology textbooks and courses. A similar survey of Canadian biology texts by Clow et $a l^{5}$ in Montreal reached virtually the same conclusions. In both reports the authors considered it important that teachers should use more human examples in teaching basic genetic principles and there should be less reliance on

\footnotetext{
*1 A First Biology Course. PT Bunyan (1982).

2 Making Sense of Science. Biology. J Hardie and C Avery (1982).

3 Modern Biology. R Soper and S Tyrell-Smith (1979).

4 Biology for Life. MBV Roberts (1981).

5 Biology. A Functional Approach. MBV Roberts (1976).

6 Life Study. A Text Book of Biology. DG Mackean (1981).
}

traditional genetic models. Despite these criticisms of textbocks, it is clear that more of them contain reference to human disease than their British equivalents and this would seem to reflect the greater medical awareness of the American public. In an excellent review of the historical and philosophical background of education in human genetics in the United States, Hurd ${ }^{6}$ listed a number of goals of any educational programme in genetic disease. These included ensuring that the students obtained sufficient biology and basic genetics to comprehend the source and meaning of the genetic disorder, understood how genetic diseases could be managed, and were made aware of the medical, social, economic, and ethical implications of genetic diseases. The full list is a very comprehensive one and, although ambitious, is important. Dr Hurd further commented that an effective genetic education programme in schools would obviously require a supporting public. He judged that there was a surge of health awareness among the American people and that their expressed desire for more effective medical delivery systems should encourage the setting up of genetic education programmes. He concluded that it would probably take at least a generation of planned and consistent educational effort to bring about sufficient concern and intellectual commitment on the part of society to help minimise the burden of genetic diseases. In the same journal in 1979, Childs ${ }^{7}$ also reviewed education in genetics for the public and the medical profession. He suggested that genetic knowledge could be used in medicine in two ways: firstly, in the classifications of disease and, secondly, in the detection of people who have qualities that make them susceptible to particular diseases. He criticised the lack of adequate education in genetic matters for medical students and, in a very persuasive manner, argued that it was important to make biology a prerequisite to the title of an educated person. He suggested that biology is not a part of the general consciousness and that most people were the victims of the 19th century tradition of classical education. He concluded that although it was necessary to press forward with education for physicians, the general public, and college students, the real key to success would lie in making human variability and its causes a central ingredient of primary and secondary education. One feels that these criticisms and recommendations could be very easily applied to the educational system in Great Britain.

Mertens et al, ${ }^{8}$ in a survey of teachers' attitudes to biology, confirmed that although teachers of biology are fairly confident of their ability to teach about classical and molecular genetics, they are less knowledgeable about recent developments and their

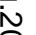
。 
impact on society. Many of the advances have created controversial social issues and the investigators attempted to assess the teachers' stance on these matters. They suggested that if teachers are to deal effectively with these, they would need instruction not only in human and medical genetics but also in the methodology of teaching controversial issues. This has obvious relevance to other professionals including genetic counsellors. A further excellent review by the Biological Science Curricula Group ${ }^{9}$ came to similar conclusions after a survey of human genetic teaching in the United States. They also concluded that human genetics instruction must receive greater attention in the classroom. They made their recommendations with an awareness of the importance of genetic diseases, the need for the public to be more aware of disease prevention, and an acceptance of the importance of disease in society. Their survey, conducted in 1977, would be even more relevant to today's problems. They recommended that a major effort shculd be made to devise new materials and strategies for the classroom teachers and for others in similar positions to improve the quantity and quality of human genetics instruction.

In England the responsibility for alterations to school science curricula rests with bodies such as the Association for Science Education, the Department of Education and Science, and others. Although, in the past, there has been little concern expressed about social issues there seems now to be a growing awareness of the need to develop the science curriculum to meet changing needs. This is confirmed by the emergence of projects such as Science In a Social Context (SISCON), the Secondary Science Curriculum Review, and a number of other projects. There is obviously a number of teachers who agree that more emphasis needs to be placed on how pupils find out about science and less emphasis on the total body of knowledge. SISCON has also commented on the impact of science upon society and the responsibility of scientists for the outcome of their work. Many of the topics they mention are complex and their politically sensitive nature is appreciated. One of their most important premises is that the teachers really should encourage pupils to make reasoned personal decisions about problems, and should see themselves as guides and arbitrators rather than purveyors of the right answer. At least one of the suggested topics in SISCON's teachers guide is on evolution. Part of this deals with some simple facts about genetics in order to make sense of moral, medical, and legal dilemmas associated with handicapped children. They also mention genetic counselling and eugenics. The Secondary Science Curriculum Review, a 5-year programme of research, has a major aim to review and develop the science curriculum from the age of 11 to 16 in order to meet better the needs of all young people. Both these projects confirm the findings from North America and would seem to be attempting to meet the demand for more science teaching.

If there is agreement on the need for more genetics in the biology courses in our schools, then teachers are obviously the correct people to up-date current teaching of basic molecular and Mendelian genetics. However, they could justifiably expect help from groups such as clinical geneticists in preparing classroom material on the sccial and medical relevance of recent advances. A report from the Clinical Genetics Society ${ }^{10}$ listed health education as one of the functions of a regional genetic service and cooperation with teachers would obviously be important. The Department of Education and Science and the Health Education Council have made some very useful recommendations over the years as to what might constitute important health issues, but so far have not been concerned with genetic matters. Now may be the right time to recommend the addition of genetic disorders to the list of health subjects for discussion in our schools. ${ }^{11}$ There has already been successful cooperation between clinical geneticists, national education associations, and curriculum developers in North America and Canada. Similar progress could be anticipated in this country, and there seems to be no lack of professional groups interested in ensuring some changes.

Developments in genetics, and their potential for disease prevention, are clearly important for our community's health. Inevitably they will have social and ethical consequences, and some of these have already been the subject of television programmes, not all of which have presented the material in an unbiased way. ${ }^{12}$ The first instalment of genetic medicine is upon us and subsequent developments will undoubtedly produce further problems. Although the media and other sources have an important part to play in alerting the public to these new developments, the responsibility for educating the next generation should be accepted by professional teachers working in cooperation with interested medical staff. There is need for a more informed public and how best to ensure this needs to be discussed. It would certainly appear time that the debate started and, although an agreed curriculum should continue to be the best for a sound education, we must hope that it does not become a machine which is worshipped for its own sake. ${ }^{13}$

The author is extremely grateful to those teachers of biology and health education who encouraged and educated him during discussions about this paper. 


\section{References}

1 Seidenfeld MJ, Braitman A, Antley RM. The determinants of mothers' knowledge of the Down syndrome before genetic counselling. Part II. Am J Med Genet 1980;6:9-23.

${ }^{2}$ Leonard CO, Chase GA, Childs B. Genetic counseling: a consumers' view. $N$ Engl J Med 1972;287:433-9.

3 Scriver CR, Scriver DE, Clow CL, et al. The education of citizens: human genetics. Am Biol Teach 1978;May:280-4.

4 Mertens TR, Bowman D. An analysis of the human genetics content of 13 general biology textbooks. J Hered $1981 ; 72: 364-8$.

5 Clow CL, Schok M, Scriver CR, et al. In: Porter IH, Hook EB, eds. Human genetics education in the high school: a working experience. Service and education in medical genetics. New York: Academic Press, 1979: 337-49.

6 Hurd PD. The historical/philosophical background of education in human genetics in the United States. Biol Sci Curr Studv J 1978;1:3-8.

7 Childs B. Education in genetics for the medical profession and the public. Biol Sci Curr Study J 1979;2:7-8.
8 Mertens TR, Hendrix JR, Henriksen LW. Biology teachers: genetics educational needs and related values stances. $J$ Hered 1979;70:161-5.

9 Hickman FM, Kennedy MH, McInerney JD. Human genetics education: results of BSCS needs assessment surveys. Am Biol Teach 1978; May:285-303.

10 Report of the Clinical Genetics Society Working Party on Regional Genetic Services. The provision of regional genetic services in the United Kingdom. Eugenics Society 1982; suppl 4.

11 Fitzsimmons JS. The need for more human genetics in biology and health education. The School Science Review (in press).

12 Glover J. Genetic engineering. Listener 1982;18 November:5-6.

13 Kennedy MH. A machine which they worship for its own sake. Am Biol Teach 1978; May: 316-28.

Correspondence and requests for reprints to Dr J S Fitzsimmons, Clinical Genetic Service, City Hospital, Hucknall Road, Nottingham NG5 1PB. 